The Bangladesh Veterinarian (2019) 36(1 - 2): 42- 48

\title{
Evaluation of pregnancy diagnosis using ultrasonography in goats
}

\author{
Azizunnesa*, MMB Reza, MA Parvez and MO Faruk ${ }^{1}$ \\ Department of Medicine and Surgery, Faculty of Veterinary Medicine, Chattogram \\ Veterinary and Animal Sciences University, Khulshi, Chattogram-4225, Bangladesh
}

\begin{abstract}
Pregnancy status in 250 goats was determined by transabdominal ultrasonography. The registered hospital cases were divided into groups A (mated naturally; 88); B (postpartum reported unmated; 112) and $C$ (pubertal unmated; 50). Animals found to be non-pregnant and free of uterine infection were labelled Group D and divided into synchronized (S) and control (NS) groups. GnRH followed byPGF2a nine days later was injected i.m. in group S, and NS group were allowed natural mating. All mated goats were checked monthly for pregnancy using ultrasonography. Pregnancy was diagnosed in 45.5, 4.5 and $0 \%$ from naturally mated, postpartum reported unmated and pubertal unmated cases, respectively. The oestrus detection and pregnancy rates varied significantly $(\mathrm{P}<0.001)$ between synchronized ( $\mathrm{n}=96 ; 70.8$ and $54.4 \%$, respectively) and NS group $(\mathrm{n}=96: 54.0$ and $28.6 \%$, respectively). Pregnancy rates significantly varied in different months in gestation $(\mathrm{P}<0.05)$. Fetal viability rate was low in 1 st month of pregnancy compared to other months $\left(2^{\text {nd }}, 3^{\text {rd }}\right.$ and $>3^{\text {rd }}$ ). The confirmation of expected date of delivery (EDD) was low in $1^{\text {st }}$ month of gestation compared to other months. Transabdominal ultrasonographic scanning helps to confirm pregnancy in goats. From $2^{\text {nd }}$ month of gestation ultrasound scanning confirms pregnancy with viable fetus $(83.3 \%)$. At $3^{\text {rd }}$ month of pregnancy, this technique determined the EDD up to 94.2\%. (Bangl. vet. 2019. Vol. 36, No. 1 - 2, 42 - 48)
\end{abstract}

\section{Introduction}

Ultrasound scanning is a common, reliable and comparatively cheap method for detection of pregnancy in animals (Gonzales-Bulnes et al., 2010). Pregnancy diagnosis in goats is challenging particularly in early stage. A reliable technique for detection of pregnancy in goats is emerging and enabling herdsman to separate non-pregnant goats and thereby save on feed, labour, vaccination, veterinary cost. Ultrasound scanning is non-invasive and causes little stress (Gonzales-Bulnes et al., 2010; Medan et al., 2004). During ultrasonographic scanning, fetal heart beats, umbilical blood flow and middle uterine artery sounds resulted in 100, 100 and 72\% accuracy of pregnancy diagnosis, respectively (Wani et al., 1998). The fetal number (Fukui et al., 1986), and estimated gestational age (Russel and Goddard, 1995) can be determined. Transrectal

\footnotetext{
1Upazila Livestock Officer, Upazila Livestock Office and Veterinary Hospital, Fatickchari, Chattogram, Bangladesh

*Corresponding author:- E-mail: msrekha04@yahoo.com
}

DOI: https://doi.org/10.3329/bvet.v36i1-2.55749 
or transabdominal ultrasonography applications can be used with nearly $100 \%$ accuracy (Mialot et al., 1991).

Medan et al. (2004) suggested that early and accurate diagnosis of pregnancy and determination of fetal number increases reproductive efficiency. Pregnancy diagnosis identifies which does require repeat service or insemination and allow the separation of pregnant females. Abdominal palpation and inspection are common practices for pregnancy diagnosis in goats in Bangladesh, but are not suitable for early detection of pregnancy.

Report on ultrasonographic scanning for pregnancy diagnosis in small ruminants are scanty. This study was designed to use ultrasonographic scanning for diagnosis of pregnancy in goats registered as outdoor patients at SAQ Teaching Veterinary Hospital (SAQTVH), Chattogram Veterinary and Animal Science University (CVASU).

\section{Materials and Methods}

\section{Animals and their grouping and management}

A total of 250 goats, Black Bengal, or Jamunapri and Black Bengal crosses, were selected from cases at Theriogenology unit at SAQTVH, CVASU from July 2018 to June 2019. Owners' history was taken. The goats were divided into group A: (88) naturally mated, B: (112) postpartum reported unmated, C: (50) pubertal unmated. Of these, 192 were found to be non-pregnant and free of uterine disease. These were labelled Group D and divided into S: (96) synchronized and NS (96) nonsynchronized. The goats were kept under traditional management system by farmers. Wheat bran, rice polish and common grazing with ad libitum water were supplied.

\section{Oestrous synchronization, heat detection and hand mated by bucks:}

Group D were divided into synchronized (S: $\mathrm{n}=96)$ and non-synchronized (NS: $\mathrm{n}=$ 96) group. S group were treated with GnRH (Fertilion ${ }^{\circledR}$, Techno Drugs Ltd, Bangladesh) and nine days later $\mathrm{PGF}_{2} \alpha$ (Ovuprost ${ }^{\circledR}$ Cloprostenol, Bomac Laboratories Ltd., New Zealand) i/m injection for oestrous synchronization. Group NS were given no treatment and kept as control. Goats of both groups were monitored for oestrous behaviour and allowed to mate with bucks.

\section{Ultrasonography for pregnancy evaluation}

Transabdominal digital ultrasonic diagnostic imaging system with convex abdominal ultrasonic transducer $5 \mathrm{MHz}$ (ExaGo, ECM, France) was used in standing position without sedation to diagnose pregnancy in goats. The right lower abdomen was clipped and shaved. Pregnancy was confirmed by observing the gestational sac, fetus, fetal part(s), cotyledon etc (Fig. 1). At $1^{\text {st }}$ month of gestation, pregnancy was confirmed by the presence of fetus and fetal heart beats. Fetal viability was measured observing fetal movement or heart beats. Expected date of delivery (EDD) was estimated by measuring sac diameter or cotyledon size or by observing fetal parts 
(Fig. 1). Evaluation of pregnancy status was done as described by Medan et al. (2004). EDD was compared with actual date of delivery obtained from owners. Pregnancy was recorded as $1^{\text {st }}, 2^{\text {nd }}$ and $3^{\text {rd }}$ months and more.
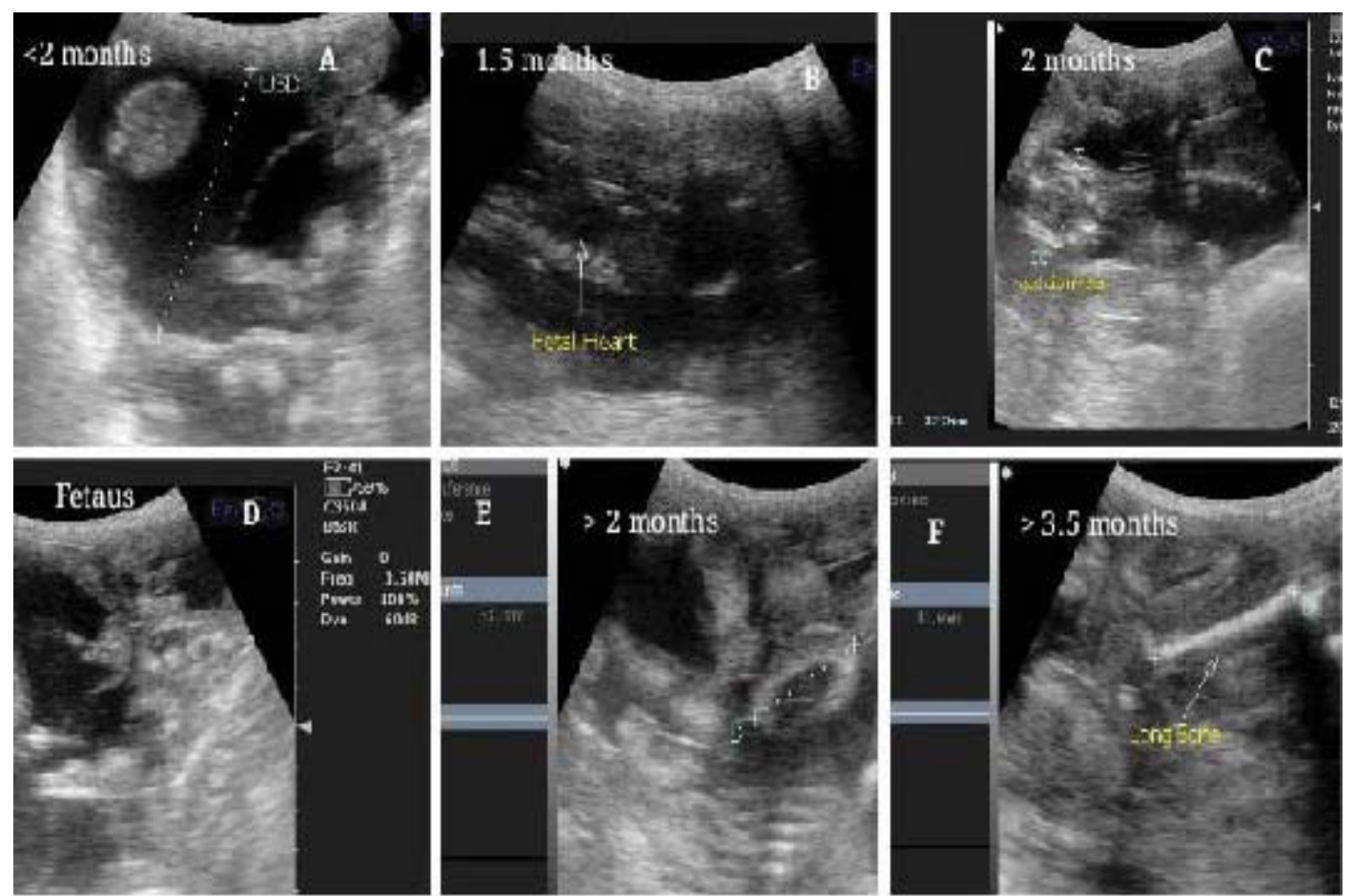

Fig. 1: Ultrasonic image of pregnancy evaluation; A. Gestational sac, B. Fetal heart, C. Head diameter, D. Fetus, E. Cotyledonesize, F. Long bone length.

\section{Statistical analysis}

The data were compiled in Microsoft Excel spreadsheet 10 (Microsoft office 2010, USA) and subjected to comparative statistical analysis with respect to oestrous synchronization, and ultrasonographic examination using STATA 13.0 (Stata Corp. 2013, USA). Fisher's exact Chi-square test was done to evaluate the effect of oestrous synchronization on oestrus and pregnancy rates compared to control. Similar test was done to observe the accuracy of detection of pregnancy and its status in different gestation periods. Significant difference was accepted at $\mathrm{P}<0.05$ level.

\section{Results and Discussion}

Out of 250 goats, 88 were naturally mated, 112 were postpartum reported unmated and 50 were pubertal unmated, respectively. In naturally mated goats, 40 (45.5\%) were pregnant, $48.9 \%$ were non-pregnant, and 5.7\% had uterine infection. Among postpartum reportedly unmated goats $4.5 \%$ were pregnant, $88.4 \%$ non-pregnant and $7.1 \%$ had uterine infections. All the pubertal unmated goats were diagnosed nonpregnant (Table 1). The pregnancy rates differed significantly between groups 
$(\mathrm{P}<0.001)$. Goats confirmed pregnant when reported might be due to mating during free grazing.

Table 1. Diagnosis of pregnancy in goats registered as outdoor patients at SAQTVH using ultrasonography scanning $(n=250)$

\begin{tabular}{l|c|c|c}
\hline \multirow{1}{*}{ Groups } & \multicolumn{3}{|c}{ Ultrasonography scanning } \\
\cline { 2 - 4 } & Pregnant & Non pregnant & Uterine infection \\
\hline A (88) & $40(45.5 \%)$ & $43(48.9 \%)$ & $5(5.7 \%)$ \\
B (112) & $5(4.5 \%)$ & $99(88.4 \%)$ & $8(7.1 \%)$ \\
C (50) & $0(0 \%)$ & $50(100 \%)$ & $0(0 \%)$ \\
P value & $<0.001$ & $<0.001$ & 0.162 \\
\hline
\end{tabular}

$\mathrm{A}=$ Naturally mated goats, $\mathrm{B}=$ Postpartum reported unmated goats, $\mathrm{C}=$ Pubertal unmated goats, $\mathrm{P} \leq 0.05$ is considered as statistically significant

In small ruminants, oestrous has been synchronized using GnRH, PGF 2 a, PMSG, FSH, and LH (Faruk et al., 2006; Monika, 2001; Rekha et al., 2016). A combination of GnRH and $\mathrm{PGF}_{2} \mathrm{a}$ is the easiest and least time-consuming method. Synchronized goats showed higher $(\mathrm{P} \leq 0.01)$ oestrus and pregnancy rates (70.8 and $54.4 \%$, respectively) than control (51.0 vs $28.6 \%$ ) (Table 2 ).

Table 2. Effects of oestrous synchronization on oestrus and pregnancy rates in goats (n $=192)$

\begin{tabular}{l|c|c|c|c|c|c|c}
\hline Group D & $\begin{array}{c}\text { No. in } \\
\text { oestrus }\end{array}$ & $\begin{array}{c}\text { Oestrous } \\
\text { rate (\%) }\end{array}$ & P value & $\begin{array}{c}\text { No. of breed } \\
\text { showed } \\
\text { oestrus }\end{array}$ & $\begin{array}{c}\text { No. of pregnancy } \\
\text { detected by } \\
\text { ultrasonography }\end{array}$ & $\begin{array}{c}\text { Pregnancy } \\
\text { rate }(\%)\end{array}$ & P value \\
\hline S (n = 96) & 68 & 70.8 & 0.011 & 68 & 37 & 54.4 & $<0.001$ \\
NS (n = 96) & 49 & 51.0 & & 49 & 14 & 28.6 & \\
\hline
\end{tabular}

$\mathrm{S}=$ Synchronized and NS $=$ Non synchronized (Control), $\mathrm{P}<0.05$ is considered statistically significant difference between $S$ and NS.

The oestrous synchronization response is similar to others (Abdalla et al., 2014; Panicker et al., 2015; Riaz et al., 2012; Zeuh et al., 2014). Hashemi and Safdarian (2018) reported $83.3 \%$ pregnancy rate after synchronizing with two doses of prostaglandin, which was higher than the present study (54.4\%). Synchronizing the goats using fluorogestone acetate-impregnated vaginal sponges induced ovulation (98.2\%) and pregnancy $(75.0 \%)$, which were higher than the present study (Freitas et al., 1996). Variation could be due to different synchronization protocols, breed, location and husbandry. Oestrus and pregnancy rates were higher in synchronized goats than in controls.

Traditional methods for pregnancy diagnosis in small ruminants are ballottement of the abdomen and noting udder enlargement in late pregnancy. Transabdominal 
ultrasonography has been used with great accuracy for pregnancy diagnosis and estimation of fetal numbers in sheep (Buckrell, 1988; Garcia et al., 1993) and goats (Gonzalez et al., 2004; Martinez et al., 1998). It is crucial to know the stage of pregnancy, to improve feeding. The results of ultrasonography scanning are presented in Table 3: scanning identified $100 \%$ of pregnant goats from $2^{\text {nd }}$ month. In the $1^{\text {st }}$ month, pregnancy detection rate was $82.8 \%$, which was significantly lower $(\mathrm{P}<0.007)$ than in other months. In the $1^{\text {st }}$ month, pregnancy was detected by observing gestational sac or fetus or fetal heart beats, which were sometimes difficult to identify. Several studies reported that accuracy in pregnancy diagnosis from 42 days of gestation was 100\% using ultrasonography (Abdelghafar et al., 2010; Amer, 2008; Anwar et al., 2008; Kumar et al., 2015; Medan et al., 2004; Omontese et al., 2012), which is consistent with present study. But Fowler and Wilkins (1984) showed 95\% accuracy in the diagnosis of pregnancy from 40 to 50 days.

Fetal viability was higher in advanced pregnancy. Samir et al. (2016) reported fetal viability at day 20 to day $54(80.4 \%)$ and at day 55 to parturition $(88.2 \%)$, which is similar to our study.

The EDD was estimated in different months of gestation, and it varied significantly $(\mathrm{P}<0.001)$. The confirmation of EDD was lower in the 1st month of gestation $(45.8 \%)$ than $2^{\text {nd }}(76.6 \%), 3^{\text {rd }}(94.2 \%)$ and above $(85.0 \%)$. In the $1^{\text {st }}$ month, it is difficult to estimate the EDD by measuring gestational sac diameter and counting fetal heart beats.

Table 3. Status of pregnancy diagnosis by ultrasonography scanning in different months of gestation in goats $(n=96)$

\begin{tabular}{l|ccc|c|c}
\hline \multirow{2}{*}{ Arameters } & \multicolumn{2}{|c}{ Ultrasonography scanning of pregnant goats (months) } & \multirow{2}{*}{ P value } \\
\cline { 2 - 5 } & $1^{\text {st }}$ & $2^{\text {nd }}$ & $3^{\text {rd }}$ & $>3^{\text {rd }}$ & \\
\hline No. of scanned goats & 29 & 30 & 17 & 20 & \\
Pregnant goats & $24(82.8 \%)$ & $30(100 \%)$ & $17(100 \%)$ & $20(100 \%)$ & 0.007 \\
Fetal viability & $19(79.2 \%)$ & $25(83.3)$ & $15(88.2 \%)$ & $18(90.0 \%)$ & 0.111 \\
EDD confirmation & $11(45.8 \%)$ & $23(76.6 \%)$ & $16(94.2 \%)$ & $17(85.0 \%)$ & $<0.001$ \\
\hline
\end{tabular}

$\mathrm{P} \leq 0.05$ is considered as statistically significant difference among different measuring parameters.

With advancing gestation fetal growth and different parts of body and cotyledons are easily visible and may help in estimating EDD.

\section{Conclusions}

Ultrasonographic scanning in goats was advantageous in pregnancy confirmation. Pregnancy was confirmed with $100 \%$ accuracy from $2^{\text {nd }}$ month of gestation with fetal viability ( 83.3 to $90 \%$ ) and estimation of EDD (76.6 to $94.2 \%)$. 


\section{Acknowledgements}

The authors acknowledge the Ministry of Science and Technology, Government of People's Republic of Bangladesh for financial support. The authors would like to thank Director, SAQTVH, CVASU and goat owners in Chattogram for their co-operation and support.

\section{References}

Abdalla EB, Farrag B, Hashem ALS, Khalil FA and Abdel-Fattah MS 2014: Effect of progestagen, PGF2a, PMSG and GnRH on estrus synchronization and some reproductive and productive traits in Barki ewes. Journal of Agroalimentary Processes and Technologies 20 93-101.

Abdelghafar RM, Ibrahim RM, Abdelharimi SM and Ahmed BH 2010: Sensitivity and specificity of real-time ultrasonography for pregnancy diagnosis and litter size in Saanen goats (Capra hircus). In: Proceedings of the 14th Scientific Congress of the Faculty of Veterinary Medicine, Assiut University, Egypt, pp. 392-401.

Amer HA 2008: Determination of first pregnancy and foetal measurements in Egyptian Baladi goats (Capra hircus). Veterinaria Italia Journal 44 429-437.

Anwar M, Riaz A, Ullah N and Rafiq M 2008: Use of ultrasonography for pregnancy diagnosis in Balkhi sheep. Pakistan Veterinary Journal 28 144-146.

Buckrell BC 1988: Application of ultrasonography in reproduction in sheep and goats. Theriogenology 29 71-84.

Faruk MO, Bari FY, Shamsuddin M, Alam MGS and Islam MF 2006: Responses of the Black Bengal goat (Capra hircus) to PMSG and surgical embryo recovery within MOET technique. Bangladesh Journal of Veterinary Medicine 4 107-115.

Fowler DG and Wilkins JF 1984: Diagnosis of pregnancy and number of fetuses in sheep by real-time ultrasonic imaging. I. Effects of number of fetuses, stage of gestation, operator and breed of ewe on accuracy of diagnosis. Livestock Production Science $\mathbf{1 1}$ 437-450.

Freitas VJF, Baril G and Saumande J 1996: Induction and synchronization of estrus in goats: the relative efficiency of one versus two fluorogestone acetate-impregnated vaginal sponges. Theriogenology 46 1251-1256.

Fukui Y, Kobayashi M, Tsubaki M, Tetsuka M, Shimoda K and Ono H 1986: Comparison of two ultrasonic methods for multiple pregnancy diagnosis in sheep and indicators of multiple pregnant ewes in the blood. Animal Reproduction Science 11 25-33.

Garcia A, Neary MK, Kelly GR and Pierson RA 1993: Accuracy of ultrasonography in early pregnancy diagnosis in the ewe. Theriogenology 39 847-861.

Gonzalez F, Cabrera F, Batista M, Rodríguez N, Alamo D, Sulon J, Beckers JF and Gracia A 2004: A comparison of diagnosis of pregnancy in the goat via transrectal ultrasound scanning, progesterone, and pregnancy-associated glycoprotein assays. Theriogenology 62 1108-1115. 
Gonzalez Bulnes A, Pallares P and Vazquez MI 2010: Ultrasonographic imaging in small ruminant reproduction. Reproduction in Domestic Animals 45 9-20.

Hashemi M and Safdarian M 2018: Efficiency of different methods of estrus synchronization followed by fixed time artificial insemination in Persian downy does. Animal Reproduction 14 413-417.

Kumar K, Chandolia RK, Kumar S, Pal M and Sandeep K 2015: Two-dimensional and three-dimensional ultrasonography for pregnancy diagnosis and antenatal fetal development in Beetal goats. Veterinary World $\mathbf{8} 835$.

Martinez MF, Bosch P and Bosch RA 1998: Determination of early pregnancy and embryonic growth in goats by transrectal ultrasound scanning. Theriogenology 49 1555-1565.

Medan M, Watanabe G, Absy G, Sasaki K, Sharawy S and Taya K 2004: Early pregnancy diagnosis by means of ultrasonography as a method of improving reproductive efficiency in goats. Journal of Reproduction and Development 50 391-397.

Mialot JP, Levy I and Emery P 1991: Ultrasound and management of goat herds. Compendium of Veterinary Medicine 168 399-406.

Monika P 2001: Ovine reproduction. In: Compendium of Animals Reproduction. Monika P (Edn), Intervet International. BV Holand, pp. 125-145.

Omontese BO, Rekwot PI, Ate IU, Rwuaan JS, Makun HJ, Mustapha RA and Lawal M 2012: Use of ultrasonography for pregnancy diagnosis in Red Sokoto goats. Scientific Journal of Biological Sciences 1 101-106.

Panicker SS, Kanjirakuzhiyil P, Koodathil R and Kanakkaparambil R 2015: Oestrous response and conception rate in Malabari crossbred goats following two different oestrus synchronization protocols. Journal of Animal Health and Production 3 39-42.

Rekha A, Zohara BF, Bari F and Alam MGS 2016: Comparison of commercial Triladyl extender with a tris-fructose-egg-yolk extender on the quality of frozen semen and pregnancy rate after transcervical AI in Bangladeshi indigenous sheep (Ovis aries). Small Ruminant Research 134 39-43.

Riaz H, Sattar A, Arshad MA and Ahmad N 2012: Effect of synchronization protocols and $\mathrm{GnRH}$ treatment on the reproductive performance in goats. Small Ruminant Research 104 151-155.

Russel AJF, Goddard PJ 1995: Small animal reproductive ultrasonography. In: Goddard PG (ed.), Veterinary Ultrasonography. CAB International, Wallingford, UK pp. 257-274.

Samir H, Karen A, Ashmawy T, Abo-Ahmed M, El-Sayed M and Watanabe G 2016: Monitoring of embryonic and fetal losses in different breeds of goats using real-time B-mode ultrasonography. Theriogenology 85 207-215.

Wani NA, Wani GM, Mufti AM and Khan MZ 1998: Ultrasonic pregnancy diagnosis in gaddi goats. Small Ruminant Research 29 239-240.

Zeuh V, Youssouf ML, Dingamtar N and Dezoumbe D 2014: Evaluation of two methods of estrus synchronization of cattle in Chad. Open Journal of Animal Sciences 45. 